\title{
A DEVOLUÇÃO DOS VALORES RECEBIDOS POR BENEFÍCIOS PREVIDENCIÁRIOS CONCEDIDOS POR TUTELA ANTECIPADA POSTERIORMENTE REVOGADA: ANÁLISE JURISPRUDENCIAL DOS TRIBUNAIS SUPERIORES BRASILEIROS
}

\author{
Maria Clara de Jesus Maniçoba Balduino ${ }^{29}$
}

Recebido em: 01/11/2019

Aprovado em: 12/02/2020

\section{RESUMO}

A possibilidade de devolução dos valores recebidos por benefícios previdenciários concedidos mediante tutela antecipada que venha a ser posteriormente revogada é tema que tem ganhado notoriedade e relevância na comunidade jurídica diante das divergências jurisprudenciais que tem se verificado nos tribunais brasileiros ao julgar tais demandas. As ações que versam sobre a concessão de benefícios previdenciários em regra demandam urgência diante da situação de necessidade e desamparo em que se encontra o requerente; além disso, o lapso temporal para que o processo previdenciário seja concluído pode colocar em risco o direito do beneficiário, podendo levar a ocorrência de um dano irreparável e irreversível na demanda. Nessas situações, não é incomum que seja requerida a antecipação de tutela para que o direito possa ser satisfeito em tempo hábil, o que ocorre no entanto é que tal decisão se dá meio de cognição sumária, e o caráter provisório da tutela implica em sua possível reversibilidade posterior. Em caso de revogação, a pergunta que se impõe é: cabe ou não a devolução desses valores? Diante disso, o presente artigo busca analisar essa possibilidade a partir de um estudo sobre instituto da tutela antecipada no processo previdenciário, verificando como os tribunais superiores brasileiros vem se manifestando sobre o assunto. Utiliza como procedimentos metodológicos a pesquisa bibliográfica em meio impresso e virtual.

Palavras-Chave: Direito Previdenciário. Benefícios Previdenciários. Processo Previdenciário. Revogação de Tutela Antecipada. Devolução Dos Valores.

\footnotetext{
${ }^{29}$ Advogada (OAB-RN 16.528). Mestranda em Direito pela Universidade Federal do Rio Grande do Norte/UFRN.
} 


\section{INTRODUÇÃO}

As lides previdenciárias que visam a obtenção de benefício previdenciário, demandam agilidade na satisfação do pedido tendo em vista o caráter de necessidade que em regra os motiva, a pessoa que pleiteia a concessão de benefício previdenciário muitas vezes encontra-se em situação de total desamparo, impossibilitado de prover seu próprio sustento, depositando todas as suas expectativas na sucesso da demanda. Neste contexto, o lapso temporal do processo previdenciário pode colocar em risco o direito do beneficiário, podendo levar a ocorrência de um dano irreparável e irreversível.

O relatório "Justiça em Números" emitido no ano passado pelo Conselho Nacional de Justiça revela o tempo aproximado de tramitação dos processos nos tribunais brasileiros, e em média, da entrada no judiciário até a emissão da sentença, os processos demoram cerca nove meses nos Juizados Especiais Federais, mais de dois anos nas varas federais, e onze meses no Superior Tribunal de Justiça ${ }^{30}$. É possível perceber, portanto, que o tempo de espera em regra é prolongado, sem contar as interposições de recurso que inserem novas contagens de prazo nesse tempo de espera.

A antecipação da tutela, muitas vezes, constitui-se nesses casos o único meio hábil de permitir a fruição do direito pelo beneficiário, para que seu pleito não reste prejudicado. Ocorre que diante da urgência da situação, a análise de tal instituto se dá por meio de cognição sumária, e o caráter provisório da tutela implica em sua possível reversibilidade ao final da demanda, o que gera uma série de consequências ao beneficiário e à administração pública.

A partir dessas considerações, o presente trabalho buscará verificar a possibilidade ou não da devolução dos valores recebidos mediante tutela antecipada que venha a ser posteriormente revogada. Para isso, buscaremos analisar os aspectos gerais do instituto da tutela antecipada, bem como sua inserção no âmbito do processo previdenciário; ademais, examinaremos o entendimento jurisprudencial dos tribunais superiores brasileiros, bem como os argumentos favoráveis e não favoráveis à devolução desses valores.

O tema releva-se de grande importância e atualidade no contexto atual, tendo em vista a controvérsia que gira em torno das divergências jurisprudenciais no judiciário brasileiro, sobretudo

30 CONSELHO NACIONAL DE JUSTIÇA, Justiça em números: 2018. Brasília, 2018. Disponível em: http://www.cnj.jus.br/files/conteudo/arquivo/2018/08/44b7368ec6f888b383f6c3de40c32167 .pdf. Acesso em: 15 ago. 2019. 
quanto ao entendimento dos tribunais superiores. Ademais, verifica-se o interesse social em se discutir o assunto por se verificar a ligação direta sobre as consequências de tais questões ao erário público.

\section{ASPECTOS GERAIS DO INSTITUTO PROCESSUAL DA TUTELA DE URGENCIA ANTECIPADA}

Nas demandas de direito previdenciário que visam a obtenção de benefício previdenciário, em regra, exigem urgência na satisfação do pedido tendo em vista o caráter de necessidade pungente que motiva seu requerimento. Neste diapasão, tendo em vista o lapso temporal extenso que muitas vezes o processo previdenciário demanda para ser concluído definitivamente, urge ao magistrado a concessão de tutela em caráter antecipatório para que a fruição do direito do requerente não reste prejudicada.

Neste sentido, interessante se faz a diferenciação de Humberto Theodoro Júnior (2002, p. 25-26) acerca da prestação jurisdicional e a tutela jurisdicional, esta segunda não em seu sentido legal estrito, mas sim em relação à ideia de completude e êxito na prestação da via jurisdicional e resguardo integral do direito pleiteado.

Para compreender melhor a temática acerca da devolução dos benefícios previdenciários indevidamente recebidos por força da revogação de tutela antecipada, necessária se faz uma análise mais perfunctória acerca do instituto da tutela antecipada, compreendendo seu conceito e classificação, bem como os elementos pressupostos à sua concessão.

\subsection{Tutela definitiva e provisória}

A tutela antecipada é subespécie da tutela provisória, e aqui cabe uma breve diferenciação ante a tutela definitiva. A tutela oferecida pelo juízo pode ser tanto definitiva como provisória, sendo que, conforme aduz Didier et. al (2017, p. 637), a definitiva “é aquela obtida com base em cognição exauriente, com profundo debate acerca do objeto da decisão [...] predisposta a produzir resultados imutáveis, cristalizados pelo coisa julgada [...] prestigia sobretudo a segurança jurídica”. 
Há situações, entretanto, em que o lapso temporal para a conclusão do processo e a determinação da coisa julgada coloca em risco a possibilidade de satisfação do pedido, ou mesmo que o direito da demanda é manifestamente evidente; nesses casos, por meio de cognição sumária o juízo poderá deferir a tutela provisória, a qual nas palavras de Neves (2018, p. 482) “é fundada em juízo de probabilidade, ou seja, não há certeza da existência do direito da parte, mas uma aparência de que esse direito exista [...] sua decisão não será fundada na certeza, mas na mera aparência - ou probabilidade - de o direito existir".

\subsection{Tutela de urgência e evidência}

A tutela provisória por sua vez divide-se em tutela de urgência ou evidência, conforme preceitua o art. 294 do Código de Processo Civil "a tutela provisória pode fundamentar-se em urgência ou evidência. Parágrafo Único. A tutela provisória de urgência, cautelar ou antecipada, pode ser concedida em caráter antecedente ou incidental”.

A tutela de evidência encontra-se disposta no art. 311 do referido Código e não depende da demonstração de perigo de dano ou de risco ao resultado útil do processo, aplicando-se a situações específicas predeterminadas (MARINONI; ARENHART; MITIDIERO,2018, P. 323).

A tutela provisória de urgência, por sua vez, conforme preleciona Elpídio Donizetti Nunes (2016, p. 498), trata-se do "provimento jurisdicional” que busca adiantar os efeitos da decisão final no processo ou assegurar seu resultado prático. Nesse sentido, o art. 300 do Código de Processo Civil delimita a tutela de urgência, ao aduzir que esta "será concedida quando houver elementos que evidenciem a probabilidade do direito e o perigo de dano ou o risco ao resultado útil do processo".

Para a caracterização da probabilidade do direito, o magistrado avaliará a razoabilidade quanto à existência do direito suscitado, bem como, conforme preleciona Didier Júnior et. al. (2017, p. 676) deverá ser levada em consideração a verossimilhança fática (que diz respeito à plausibilidade dos fatos narrados pelo autor) analisando a aceitabilidade da "verdade" trazida por ele, independentemente da produção de provas; juntamente com a plausibilidade jurídica, que diz respeito à "provável subsunção dos fatos à norma invocada". Trata-se do instituto do fumus boni iuris, ou "fumaça do bom direito". O perigo na demora encontra-se diretamente ligado à efetividade 
da jurisdição e à eficácia na satisfação do direito pretendido, definido pelo legislador como "risco ao resultado útil do processo".

\subsubsection{Tutela cautelar e antecipada}

A tutela provisória de urgência se subdivide ainda em tutela cautelar e tutela antecipada. A tutela cautelar tem por fim evitar danos, de regra presente nas tutelas ressarcitórias, ou assegurar a utilidade do processo, e ela poderá ser efetivada, conforme art. 301 do Código de Processo Civil, "mediante arresto, sequestro, arrolamento de bens, registro de protesto contra alienação de bem e qualquer outra medida idônea para asseguração do direito".

Finalmente, a tutela antecipada, objeto de estudo do tema em controvérsia, trata-se de "tutela provisória satisfativa antecipa os efeitos da tutela definitiva satisfativa, conferindo eficácia imediata ao direito afirmado. Adianta-se assim, a satisfação do direito, com a atribuição do bem da vida. Esta é a espécie de tutela provisória que o legislador resolveu denominar de tutela antecipada" (DIDIER ET AL., 2017, P. 645).

\section{PROCESSO PREVIDENCIÁRIO}

Dentro de um contexto de Estado Democrático de Direito, a administração pública, ao tomar suas decisões deve sempre levar em consideração o respeito aos direitos e garantias individuais daqueles que buscam sua prestação. José Savaris (2011, p. 149). aponta que o exercício da competência administrativas deve além de respeitar as normas do processo administrativo em si, atentar ao princípios judiciais correlatos, tais como o respeito ao devido processo legal.

Em se tratando de um processo administrativo previdenciário, "vale ressaltar que o processo administrativo previdenciário se trata de uma relação jurídico-previdenciária na qual o interesse público em questão é a proteção social frente a um estado de necessidade ou de risco de seus tutelados" (GOMES, 2019, p. 155). Savaris (2017, p. 155) aponta que a análise do conteúdo do processo administrativo previdenciário aponta ao fato que dá o deslinde à sequência de atos administrativos voltados à tutela de um bem previdenciário. 
Savaris atenta ainda para a necessidade de distinção entre processo e procedimento, para que se consiga determinar a partir de que ponto se constituiria de fato um processo administrativo. Kertzman (2012, p. 75) aponta que o início do processo se dá com a solicitação da prestação, ou seja, do requerimento dos benefícios, e estes poderão ser solicitados pelas mais diversas vias disponibilizadas pela Previdência Social, como internet, telefone e mesmo das agências do INSS.

A Instrução Normativa INSS/PRES no 77/2015 ao tratar do Processo Administrativo Previdenciário, por sua vez, em seu art. 648 preceitua processo administrativo previdenciário como:

Art. 658. Considera-se processo administrativo previdenciário o conjunto de atos administrativos praticados nos Canais de Atendimento da Previdência Social, iniciado em razão de requerimento formulado pelo interessado, de ofício pela Administração ou por terceiro legitimado, e concluído com a decisão definitiva no âmbito administrativo.

Parágrafo único. O processo administrativo previdenciário contemplará as fases inicial, instrutória, decisória e recursal (grifo nosso).

Após a fase inicial, dá-se início à fase instrutória, onde se admitem dos interessados os meios de prova que visam esclarecer sobre a existência do direito ao recebimento do benefício. Nesse momento o INSS poderá realizar diligências para atestar a veracidade ou contemporaneidade dos documentos apresentados, conforme preza o art. 685 da referida instrução normativa.

Concluída a fase de instrução, a unidade de atendimento do INSS deverá decidir sobre a questão em até 30 dias, salvo motivo expressamente justificado. Vale salientar, que conforme reza o art. 687, o INSS deve conceder o melhor benefício a que o segurado fizer jus, cabendo ao servidor orientar o beneficiário nesse sentido (BALERA; RAEFFRAY, 2012, p. 81).

Finalmente, concluída a fase decisória, abre-se a fase recursal, a qual, conforme art. 305 do Regulamento da Previdência Social, “das decisões do INSS nos processos de interesse dos beneficiários caberá recurso para o CRPS" (Conselho de Recursos da Previdência Social). Deste modo, quando requerente do benefício é notificado da decisão administrativa e é aberto prazo para recurso de 30 dias para que ele entre com o recuso junto às juntas de recursos do CRPS (BALERA; RAEFFRAY, 2012, p. 297).

\subsection{Prévio requerimento administrativo e processo judicial}

O requerimento à priori da concessão do benefício via processo administrativo constitui pré-requisito para que seja ajuizada demanda judicial caso haja indeferimento do benefício, um 
degrau obrigatório pelo qual o beneficiário necessita perpassar para que se possa buscar o pleito judicial.

Este foi o entendimento firmado pelo STF no tema 350 - "Prévio requerimento administrativo como condição para o acesso ao Judiciário", que teve como Leading Case o Recurso Extraordinário RE 631240 RG/MG por meio do qual foi conhecida a Repercussão Geral do tema.

Ementa: RECURSO EXTRAORDINÁRIO. REPERCUSSÃO GERAL. PRÉVIO REQUERIMENTO ADMINISTRATIVO E INTERESSE EM AGIR. 1. A instituição de condições para o regular exercício do direito de ação é compatível com o art. $5^{\circ}, \mathrm{XXXV}$, da Constituição. Para se caracterizar a presença de interesse em agir, é preciso haver necessidade de ir a juízo. 2. A concessão de benefícios previdenciários depende de requerimento do interessado, não se caracterizando ameaça ou lesão a direito antes de sua apreciação e indeferimento pelo INSS, ou se excedido o prazo legal para sua análise. É bem de ver, no entanto, que a exigência de prévio requerimento não se confunde com o exaurimento das vias administrativas. 3. A exigência de prévio requerimento administrativo não deve prevalecer quando o entendimento da Administração for notória e reiteradamente contrário à postulação do segurado. [....] (RE 631240, Relator(a): Min. ROBERTO BARROSO, Tribunal Pleno, julgado em 03/09/2014, ACÓRDÃO ELETRÔNICO REPERCUSSÃO GERAL - MÉRITO DJe-220 DIVULG 07-11-2014 PUBLIC 10-11-2014)

Verifica-se, portanto, que deve haver o prévio requerimento administrativo, ressalvadas algumas situações como quando o entendimento da Administração for notoriamente contrário o pleito do requerente. Em suma, com este entendimento sobre a necessidade de prévio requerimento administrativo buscou-se viabilizar o atendimento ao pleito do requerente de forma mais simples e em tese mais célere, ao mesmo tempo em que evita o abalroamento do judiciário com demandas repetitivas e cotidianas.

Caso o pleito do beneficiário não seja satisfeito pela via administrativa, este então poderá recorrer à via judicial. A competência para o julgamento das ações que versarem sobre benefícios previdenciários será da Justiça Federal, conforme determina o art. 109 da Constituição Federal: “as causas em que a União, entidade autárquica ou empresa pública federal forem interessadas na condição de autoras, rés, assistentes ou oponentes, exceto as de falência, as de acidentes de trabalho e as sujeitas à Justiça Eleitoral e à Justiça do Trabalho".

Essa competência se dá, conforme ensina Kertzman (2012, p. 302), tendo em vista que a Lei Orgânica da Previdência Social ao definir a natureza jurídica das instituições de previdência social em seu art. 119, pontuou que as instituições de previdência social constituem serviço público descentralizado da União e tem personalidade jurídica de natureza autárquica, aí se enquadrando o Instituto Nacional do Seguro Social (INSS). 
No entanto, visando proteger o segurado, o constituinte fixou no $\S 3^{\circ}$ do art. 109 da Constituição Federal a possibilidade de serem "processadas e julgadas na justiça estadual, no foro do domicílio dos segurados ou beneficiários, as causas em que forem parte instituição de previdência social e segurado, sempre que a comarca não seja sede de vara do juízo federal". Cabe ainda resguardar a competência dos Juizados Especiais Federais definida no art. $3^{\circ}$ da Lei 10.259/2001 para processar, conciliar e julgar causas de competência da Justiça Federal até o valor de sessenta salários mínimos.

\subsection{Tutela de urgência nas lides previdenciárias}

Nas lides previdenciárias que visam a obtenção de benefício previdenciário, como já posto anteriormente, demandam agilidade na satisfação do pedido tendo em vista o caráter de necessidade que em regra os motivam. Em ações que requeiram benefício de auxílio-doença, aposentadoria por invalidez ou benefício de prestação continuada por exemplo, se inserem em situações complexas da vida do requerente, e refletem um caráter de urgência diante da natureza alimentar do benefício solicitado.

Nesse diapasão, vale pontuar que o Supremo Tribunal Federal (STF), por meio da Ação Declaratória de Constitucionalidade $\mathrm{n}^{\circ}$ 4, declarou a constitucionalidade do Lei $\mathrm{n}^{\circ}$ 9.494, de 10 de setembro de 1997 que "disciplina a aplicação da tutela antecipada contra a Fazenda Pública, altera a Lei $n^{\circ} 7.347$, de 24 de julho de 1985, e dá outras providências", na qual em seu art. $1^{\circ}$ encontrase uma série de restrições previstas à concessão da tutela provisória contra a Fazenda Pública (GOMES, , 2019, p. 19).

No entanto, nos acórdãos julgados posteriormente, o STF passou a afastar tal interpretação quanto às tutelas antecipadas em ações de natureza previdenciária. A partir de então o egrégio tribunal passou a receber reclamações para que mantivesse o entendimento firmado no julgamento da citada ADC, de modo que as restrições da Lei n 9.494/97 abarcasse também as lides de matéria previdenciária "sob a alegação de que as parcelas previdenciárias seriam também vantagens funcionais"(FONSECA, 2015, p. 359).

O STF manteve a tese de que permaneceria o firmado na $\mathrm{ADC} \mathrm{n}{ }^{\circ} 4$, com exceção das ações de matéria previdenciária, conforme vinha decidindo em seus acórdãos, entendendo ser perfeitamente possível a concessão de tutela antecipada contra a Fazenda Pública nestes casos. Para 
solidificar tal posicionamento, em sessão plenária de 26.11.2003, o STF editou a Súmula 729 com a seguinte redação: "A decisão na ADC-4 não se aplica à antecipação de tutela em causa de natureza previdenciária".

Deste modo, em suma, apesar da Lei no 9.494/97 trazer uma série de restrições impostas à aplicação da tutela antecipada contra a Fazenda Pública, tais restrições não se aplicam às tutelas concedidas em matéria previdenciária, conforme solidificou a súmula 729 do STF.

\section{DEVOLUÇÃO dOS VALORES RECEBIDOS EM RAZÃo DE BENEFÍCIOS PREVIDENCIÁRIOS CONCEDIDOS POR TUTELA ANTECIPADA POSTERIORMENTE REVOGADA}

Grande controvérsia reside na divergência jurisprudencial dos Tribunais Superiores brasileiros acerca da devolução ou não das verbas previdenciárias concedidas por tutela antecipada que a venha a ser posteriormente revogada.

O Supremo Tribunal Federal e o Superior Tribunal de Justiça por grande tempo adotaram posicionamento diametralmente opostos, o primeiro defendia não haver a necessidade devolução dos valores em razão de questões relacionadas à natureza alimentar do benefício, bem como a garantia do mínimo, a depender da boa-fé do beneficiários nessas situações; o segundo defendia (e ainda defende) que deveria haver a devolução dos valores recebidos, tendo em vista a precariedade do instituto que os concede, e ainda a vedação ao enriquecimento sem causa.

Nesse diapasão, os Tribunais Regionais Federais passaram a oscilar em seu posicionamento, parte deles seguindo o entendimento do STJ e parte seguindo o do STF, gerando um claro contexto de insegurança jurídica, provocada pela controversa gerada pela falta de alinhamento entre o posicionamento dos tribunais superiores.

Nos últimos anos, a controvérsia ganhou ainda mais destaque tendo em vista a mudança de paradigma do STF, e a discussão de repercussão geral sobre o assunto que veremos a seguir.

\subsection{Entendimento jurisprudencial do STF: Argumentos não favoráveis à devolução das verbas previdenciárias}


O Supremo Tribunal Federal em decisão proferida firmou o sentido da não devolução dos valores recebidos por força de decisão judicial antecipatória dos efeitos da tutela, com base no argumento da irrepetibilidade dos valores pelo caráter alimentar do benefício. Vejamos:

EMENTA DIREITO PREVIDENCIÁRIO. BENEFÍCIO RECEBIDO POR FORÇA DE DECISÃO JUDICIAL. DEVOLUÇÃO. ART. 115 DA LEI 8.213/91. IMPOSSIBILIDADE. BOA-FÉ E CARÁTER ALIMENTAR. ALEGAÇÃO DE VIOLAÇÃO DO ART. 97 DA CF. RESERVA DE PLENÁRIO: INOCORRÊNCIA. ACÓRDÃO RECORRIDO PUBLICADO EM 22.9.2008. A jurisprudência desta Corte firmou-se no sentido de que o benefício previdenciário recebido de boa-fé pelo segurado em virtude de decisão judicial não está sujeito à repetição de indébito, dado o seu caráter alimentar. Na hipótese, não importa declaração de inconstitucionalidade do art. 115 da Lei 8.213/91, o reconhecimento, pelo Tribunal de origem, da impossibilidade de desconto dos valores indevidamente percebidos. Agravo regimental conhecido e não provido. (ARE 734199 AgR, Relator(a): Min. ROSA WEBER, Primeira Turma, julgado em 09/09/2014, PROCESSO ELETRÔNICO DJe-184 DIVULG 22-09-2014 PUBLIC 23-09-2014)

"DIREITO PREVIDENCIÁRIO. AGRAVO REGIMENTAL EM RECURSO EXTRAORDINÁRIO COM AGRAVO. BENEFÍCIO PREVIDENCIÁRIO. NATUREZA ALIMENTAR. RECEBIMENTO DE BOA-FÉ EM DECORRÊNCIA DE DECISÃO JUDICIAL. TUTELA ANTECIPADA REVOGADA. DEVOLUÇÃO. 1 . A jurisprudência do Supremo Tribunal Federal já assentou que o benefício previdenciário recebido de boa-fé pelo segurado, em decorrência de decisão judicial, não está sujeito à repetição de indébito, em razão de seu caráter alimentar. Precedentes. 2. Decisão judicial que reconhece a impossibilidade de descontos dos valores indevidamente recebidos pelo segurado não implica declaração de inconstitucionalidade do art. 115 da Lei ${ }^{\circ}$ 8.213/1991. Precedentes. 3. Agravo regimental a que se nega provimento" (ARE ${ }^{\circ}$ 734.242/DF-AgR, Primeira Turma, Relator o Ministro Roberto Barroso, DJe de 8/9/15).

Durante certo tempo, o STF manteve tal entendimento consolidado, o que gerou embate face o posicionamento do STJ, e repercutiu nas esferas dos tribunais inferiores, os quais passaram a aplicar tais argumentos

\subsubsection{Natureza Alimentar do Benefício Previdenciário}

O principal argumento utilizado em desfavor da devolução dos valores recebidos é o da alegação de sua irrepetibilidade em razão da natureza de caráter alimentar dos benefícios auferidos. Nesse sentido, a Constituição Federal, em seu artigo 100, $§ 1^{\circ}$, aponta que as verbas previdenciárias possuem natureza alimentar:

Art. 100. Os pagamentos devidos pelas Fazendas Públicas Federal, Estaduais, Distrital e Municipais, em virtude de sentença judiciária, far-se-ão exclusivamente na ordem cronológica de apresentação dos precatórios e à conta dos créditos respectivos, proibida a designação de casos ou de pessoas nas dotações orçamentárias e nos créditos adicionais abertos para este fim. 
$\S 1^{\circ}$ Os débitos de natureza alimentícia compreendem aqueles decorrentes de salários, vencimentos, proventos, pensões e suas complementações, benefícios previdenciários e indenizações por morte ou por invalidez, fundadas em responsabilidade civil, em virtude de sentença judicial transitada em julgado, e serão pagos com preferência sobre todos os demais débitos, exceto sobre aqueles referidos no $\S 2^{\circ}$ deste artigo (grifo nosso).

Savaris (2011, p. 60), por sua vez, trata o direito à previdência social como um direito fundamental, sendo o bem jurídico que este tutela um bem absolutamente indispensável ao indivíduo que o busca, tendo em vista se tratar de uma necessidade imperiosa da qual depende a dignidade de vida do beneficiário, de fato revestindo da intrisecalidade de natureza alimentar, tendo em vista que se destina a prover recursos de subsistência digna, a suprir as necessidades primárias, vitais tais como alimentação, saúde, higiene, vestuário, transporte, moradia, de modo que "o que está em jogo em uma ação previdenciária são valores sine qua non para a sobrevivência de modo decente. É o direito de não depender da misericórdia ou auxílio de outrem (SAVARIS, 2011, p. $60)$.

A justificativa é a de que à época em que foram recebidos, forma de máxima necessidade ao beneficiário, “ora, se os valores recebidos, ainda que indevidamente, são necessários para a sobrevivência do segurado, não há como obrigá-lo a devolver tais verbas, se depende delas para a sua alimentação ou aquisição de medicamentos essenciais, por exemplo" (DESTRO, 2018, p. 51). Nesse sentido Savaris (2011, p. 61) aponta ainda que a proteção social se coaduna como a própria expressão da dignidade humana quando propicia a segurança no momento que mais lhe precise, "na hipótese de cessação da fonte primária de sua subsistência". O juiz federal Omar Chamon (2018, p. 8) corrobora ainda com essa tese ao afirmar que "A irrepetibilidade da verba alimentar é razoável, pois se presume que referida verba é utilizada para garantir o extrato material mínimo para que uma pessoa viva com dignidade."

Balera e Raeffray (2012, p. 261) inclusive apontam que apesar de as ações que versam sobre benefícios previdenciários não se confundirem com as ações de alimentos, que possuem rito próprio previsto na Lei $\mathrm{n}^{\circ} 5.478 / 1968$, elas também deveriam possuir rito processual próprio e específico em razão do caráter tão peculiar de sua natureza.

\subsubsection{Boa-fé e segurança jurídica}

José Savaris (2011, p. 344) aponta ainda que a irrepetibilidade não decorre apenas da natureza alimentar do benefício, conforme já salientado, mas aliado a isto encontra-se a boa-fé do 
indivíduo, resguardado no pilar da segurança jurídica, do qual em tese decorre a confiança do cidadão na atuação estatal. Ao tratar claramente da revogação de tutela antecipada, o autor aponta que "seria uma exigência excessiva a imposição ao hipossuficiente de que, em contingência adversa, provisionasse os valores de que necessitava para subsistir, de modo a resguardar-se contra eventual inversão de rumo no processo[...]".

A professora Luiza Netto ao discorrer sobre os limites à autotutela da Administração Pública, fazendo um elo entre a legalidade estrita, a segurança jurídica e o princípio da boa fé aponta que em alguns casos é possível que o princípio da legalidade estrita deve ceda a fim de resguardar os demais, de modo que se admita priorizar a análise contextual de uma realidade concreta, preterindo regras jurídicas "para considerar uma situação nascida em confronto com tais artigos - rectius, regras - consolida- da em virtude do decurso de tempo e da necessidade de estabilidade das relações sociais" (PINTO NETTO, 2006, p. 127).

Nesse sentindo, a ministra Carmén Lucia (STF), no julgamento Mandado de Segurança (MS) 26085, impetrado por professor aposentado pela Universidade Federal da Paraíba há mais de 15 anos, cujo registro de aposentadoria foi considerado ilegal pelo Tribunal de Contas e determinado a ressarcir o erário em quase duzentos mil reais, decidiu pela suspensão da devolução dos valores supostamente recebidos indevidamente, com base no princípio da boa-fé do beneficiado $^{31}$.

\subsubsection{Mudança de Paradigma no STF: Não conhecimento de repercussão geral do Tema}

Por meio da discussão do Tema 799 a qual tratava da "Possibilidade da devolução de valores recebidos em virtude de tutela antecipada posteriormente revogada", que teve como Leading Case o ARE 722421 (Recurso extraordinário em que se discute, à luz dos arts. 5º I, XXXV, XXXVI, LV, e 195, § 5º da Constituição Federal, a possibilidade, ou não, da devolução de valores recebidos em virtude de tutela antecipada posteriormente revogada) o STF firmou a tese de não conhecimento desses casos, por se tratar de matéria infraconstitucional:

Ementa: RECURSO EXTRAORDINÁRIO COM AGRAVO. PREVIDENCIÁRIO E PROCESSUAL CIVIL. VALORES RECEBIDOS EM VIRTUDE DE CONCESSÃO DE ANTECIPAÇÃO DE TUTELA POSTERIORMENTE REVOGADA. DEVOLUÇÃO.

\footnotetext{
${ }^{31}$ BRASIL. STF. Supremo mantém liminarmente acumulação de aposentadoria de professor. Disponível em: http://m.stf.gov.br/portal/noticia/verNoticiaDetalhe.asp?idConteudo=67610. Acesso em: 15 jul. 2019.
} 
MATÉRIA DE ÍNDOLE INFRACONSTITUCIONAL. OFENSA INDIRETA À CONSTITUIÇÃO. REPERCUSSÃO GERAL. INEXISTÊNCIA. I - O exame da questão constitucional não prescinde da prévia análise de normas infraconstitucionais, o que afasta a possibilidade de reconhecimento do requisito constitucional da repercussão geral. II Repercussão geral inexistente. (ARE 722421 RG, Relator(a): Min. MINISTRO PRESIDENTE, julgado em 19/03/2015, ACÓRDÃO ELETRÔNICO DJe-061 DIVULG 27-03-2015 PUBLIC 30-03-2015 )

Ademais, ao retirar-se deste cenário, o STF implicitamente deixa a cargo a competência ao STJ para decidir sobre o imbróglio e manifestar seu posicionamento como magnânimo. Esse foi inclusive o sentido do pronunciamento de Edson Fachin na RE: 1148120 PR em 11/09/2018, ao negar recurso extraordinário interposto em face de acórdão da $4^{\mathrm{a}}$ Turma Recursal do Tribunal Regional Federal da $4^{\mathrm{a}}$ Região:

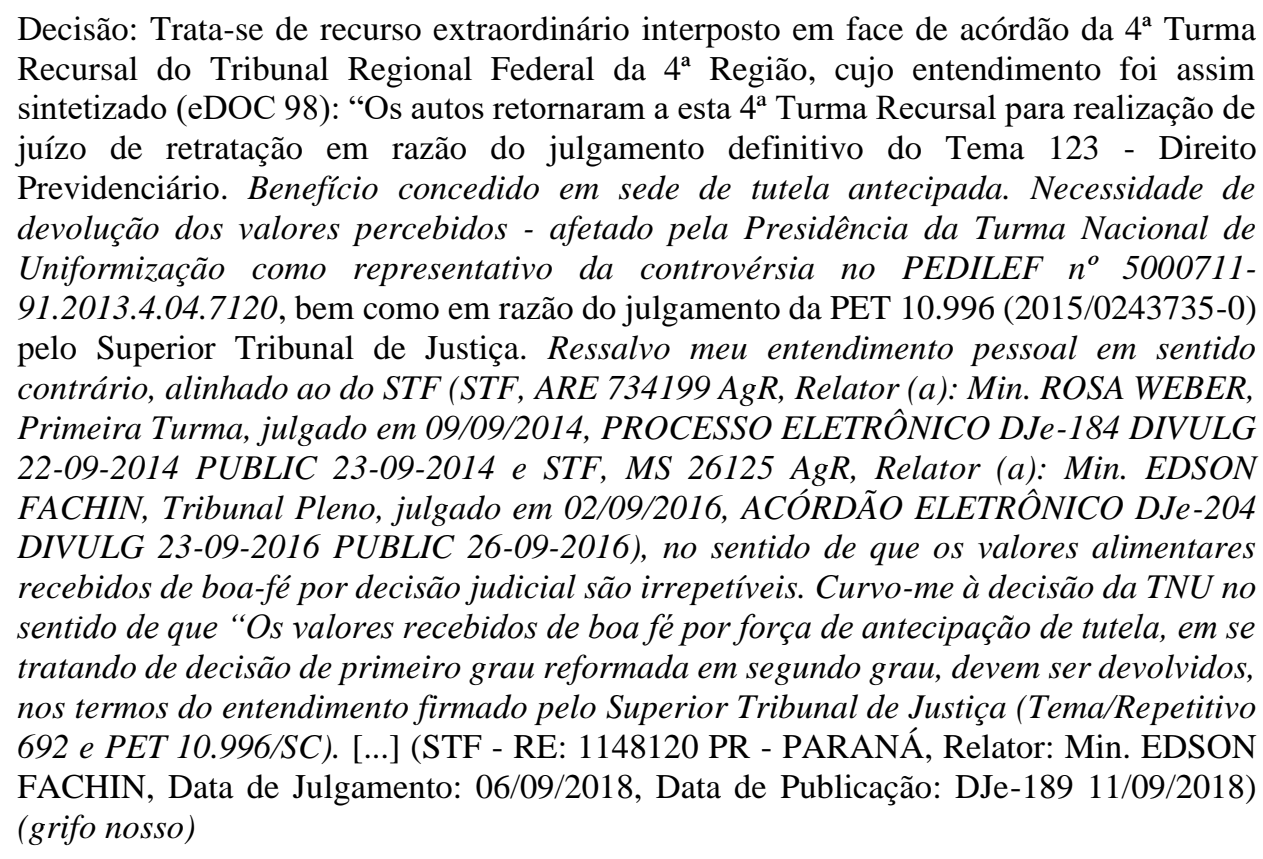

Assim, percebe-se que apesar de o Supremo Tribunal Federal possuir entendimento anterior pela irrepetibilidade dos valores recebidos por verbas previdenciárias concedidas por tutela antecipada posteriormente revogada, em razão da natureza alimentar das verbas e com base na boafé do beneficiário; o paradigma muda a partir da ARE 722421, quando o egrégio Tribunal decidiu pela não admissibilidade de tais casos por se tratar de matéria infraconstitucional, deixando a partir de então, a solução à cargo do posicionamento do STJ.

\subsection{Entendimento jurisprudencial do STJ: argumentos favoráveis à devolução das verbas previdenciárias}


A partir de uma análise jurisprudencial que apresentaremos a seguir, é possível perceber que o entendimento atual do Superior Tribunal de Justiça se dá no sentido da necessidade de devolução dos valores recebidos por antecipação de tutela posteriormente revogada.

Tal posicionamento foi uniformizado no âmbito do Superior Tribunal de Justiça (STJ) através da Discussão do Tema Repetitivo de n. 692 e que teve como Leading Case o REsp n ${ }^{\circ}$ $1.401 .560^{32}$. A questão em julgamento foi a proposta de Revisão de Entendimento firmado em tese repetitiva firmada pela Primeira Seção relativa ao Tema 692/STJ, quanto à devolução dos valores recebidos pelo litigante beneficiário em virtude de decisão judicial precária, que venha a ser posteriormente revogada e a tese firmada foi de que "a reforma da decisão que antecipa a tutela obriga o autor da ação a devolver os benefícios previdenciários indevidamente recebidos":

PREVIDÊNCIA SOCIAL. BENEFÍCIO PREVIDENCIÁRIO. ANTECIPAÇÃO DE TUTELA. REVERSIBILIDADE DA DECISÃO. O grande número de ações, e a demora que disso resultou para a prestação jurisdicional, levou o legislador a antecipar a tutela judicial naqueles casos em que, desde logo, houvesse, a partir dos fatos conhecidos, uma grande verossimilhança no direito alegado pelo autor. O pressuposto básico do instituto é a reversibilidade da decisão judicial. Havendo perigo de irreversibilidade, não há tutela antecipada (CPC, art. 273, $\S 2^{\circ}$ ). Por isso, quando o juiz antecipa a tutela, está anunciando que seu decisum não é irreversível. Mal sucedida a demanda, o autor da ação responde pelo recebeu indevidamente. $O$ argumento de que ele confiou no juiz ignora o fato de que a parte, no processo, está representada por advogado, o qual sabe que a antecipação de tutela tem natureza precária. Para essa solução, há ainda o reforço do direito material. Um dos princípios gerais do direito é o de que não pode haver enriquecimento sem causa. Sendo um princípio geral, ele se aplica ao direito público, e com maior razão neste caso porque o lesado é o patrimônio público. $O$ art. 115, II, da Lei $n^{\circ}$ 8.213, de 1991, é expresso no sentido de que os benefícios previdenciários pagos indevidamente estão sujeitos à repetição. Uma decisão do Superior Tribunal de Justiça que viesse a desconsiderá-lo estaria, por via transversa, deixando de aplicar norma legal que, a contrario sensu, o Supremo Tribunal Federal declarou constitucional. Com efeito, o art. 115, II, da Lei n ${ }^{\circ} 8.213$, de 1991, exige o que o art. 130, parágrafo único na redação originária (declarado inconstitucional pelo Supremo Tribunal Federal - ADI 675) dispensava. Orientação a ser seguida nos termos do art. 543-C do Código de Processo Civil: a reforma da decisão que antecipa a tutela obriga o autor da ação a devolver os benefícios previdenciários indevidamente recebidos. Recurso especial conhecido e provido.(STJ - REsp: 1401560 MT 2012/0098530-1, Relator: Ministro SÉRGIO KUKINA, Data de Julgamento: 12/02/2014, S1 - PRIMEIRA SEÇÃO, Data de Publicação: DJe 13/10/2015) (grifo nosso).

A partir do entendimento firmado, o STJ passou a decidir com base nesse posicionamento em casos semelhantes, conforme é possível averiguar pela apreciação de julgados mais recentes:

\footnotetext{
${ }^{32}$ Superior Tribunal de Justiça. Tema Repetitivo 692. Disponível em: http://www.stj.jus.br/repetitivos/temas_repetitivos/pesquisa.jsp?novaConsulta=true\&tipo_pesquisa=T\&sg_classe=R Esp\&num_processo_classe=1401560. Acesso em: 19 jul. 2019.
} 
RECURSO ESPECIAL No 1.756.460 - MT (2018/0188088-0) RELATORA : MINISTRA PRESIDENTE DO STJ RECORRENTE : INSTITUTO NACIONAL DO SEGURO SOCIAL RECORRIDO : NAIR DOS SANTOS CAMARGO ADVOGADO : REINALDO LUCIANO FERNANDES - MT012849A DECISÃO Vistos, etc. Trata-se de recurso especial interposto pelo INSTITUTO NACIONAL DO SEGURO SOCIAL, com fundamento no art. 105, inciso III, alínea a, da Constituição Federal, contra o acórdão proferido pelo Tribunal Regional Federal da $1 .{ }^{a}$ Região, que decidiu que não é necessária a devolução dos valores recebidos em virtude de tutela antecipada posteriormente revogada em razão da natureza alimentar dos benefícios previdenciários e da boa-fé do segurado. [...]. Decido. A Primeira Seção do Superior Tribunal de Justiça, no julgamento do Tema n. ${ }^{\circ}$ 692, vinculado ao Recurso Especial Repetitivo n. ${ }^{\circ}$ 1.401.560/MT, firmou entendimento no sentido de que "a reforma da decisão que antecipa a tutela obriga o autor da ação a devolver os benefícios previdenciários indevidamente recebidos", nos termos da seguinte ementa: "PREVIDÊNCIA SOCIAL. BENEFÍCIO PREVIDENCIÁRIO. ANTECIPAÇÃO DE TUTELA. REVERSIBILIDADE DA DECISÃO. O grande número de ações, e a demora que disso resultou para a prestação jurisdicional, levou o legislador a antecipar a tutela judicial naqueles casos em que, desde logo, houvesse, a partir dos fatos conhecidos, uma grande verossimilhança no direito alegado pelo autor. $O$ pressuposto básico do instituto é a reversibilidade da decisão judicial. Havendo perigo de irreversibilidade, não há tutela antecipada (CPC, art. 273, $\$ 2^{\circ}$ ). Por isso, quando o juiz antecipa a tutela, está anunciando que seu decisum não é irreversível. Mal sucedida a demanda, o autor da ação responde pelo recebeu indevidamente. $\mathrm{O}$ argumento de que ele confiou no juiz ignora o fato de que a parte, no processo, está representada por advogado, o qual sabe que a antecipação de tutela tem natureza precária. Para essa solução, há ainda o reforço do direito material. Um dos princípios gerais do direito é o de que não pode haver enriquecimento sem causa. Sendo um princípio geral, ele se aplica ao direito público, e com maior razão neste caso porque o lesado é o patrimônio público. $\mathrm{O}$ art. 115, II, da Lei $n^{\circ}$ 8.213, de 1991, é expresso no sentido de que os benefícios previdenciários pagos indevidamente estão sujeitos à repetição. Uma decisão do Superior Tribunal de Justiça que viesse a desconsiderá-lo estaria, por via transversa, deixando de aplicar norma legal que, a contrario sensu, o Supremo Tribunal Federal declarou constitucional. Com efeito, o art. 115, II, da Lei ${ }^{\circ} 8.213$, de 1991, exige o que o art. 130, parágrafo único na redação originária (declarado inconstitucional pelo Supremo Tribunal Federal - ADI 675) dispensava. Orientação a ser seguida nos termos do art. 543-C do Código de Processo Civil: a reforma da decisão que antecipa a tutela obriga o autor da ação a devolver os benefícios previdenciários indevidamente recebidos. Recurso especial conhecido e provido." (REsp 1.401.560/MT, Rel. Ministro SÉRGIO KUKINA, Rel. p/ Acórdão Ministro ARI PARGENDLER, PRIMEIRA SEÇÃO, julgado em 12/02/2014, DJe 13/10/2015). Na espécie, o acórdão combatido diverge dessa orientação na medida em que decidiu que não são repetíveis os valores relativos aos benefícios previdenciários pagos por força de tutela antecipada posteriormente revogada. Ante o exposto, DOU PROVIMENTO ao recurso especial para determinar a devolução dos valores indevidamente recebidos por força de tutela antecipada, posteriormente revogada. Publique-se. Intimem-se. Brasília (DF), 10 de agosto de 2018. MINISTRA LAURITA VAZ Presidente (STJ - REsp: 1756460 MT 2018/0188088-0, Relator: Ministra LAURITA VAZ, Data de Publicação: DJ 17/08/2018). (grifo nosso)

RECURSO ESPECIAL No 1.754 .580 - RS (2018/0180841-1) RELATORA : MINISTRA PRESIDENTE DO STJ RECORRENTE : INSTITUTO NACIONAL DO SEGURO SOCIAL RECORRIDO : ANDERSON MARTINS DA ROSA ADVOGADO : MAURO ANTONIO VOLKMER - RS030018 DECISÃO Vistos, etc. Trata-se de recurso especial interposto pelo INSTITUTO NACIONAL DO SEGURO SOCIAL, com fundamento no art. 105, inciso III, alínea a, da Constituição Federal, contra o acórdão proferido pelo Tribunal Regional Federal da 4. ${ }^{a}$ Região, que decidiu que não é necessária a devolução dos valores recebidos em virtude de tutela antecipada posteriormente revogada em razão 
da natureza alimentar dos benefícios previdenciários e da boa-fé do segurado. [...]. Decido. A Primeira Seção do Superior Tribunal de Justiça, no julgamento do Tema n. ${ }^{\circ}$ 692, vinculado ao Recurso Especial Repetitivo n. ${ }^{\circ}$ 1.401.560/MT, firmou entendimento no sentido de que "a reforma da decisão que antecipa a tutela obriga o autor da ação a devolver os benefícios previdenciários indevidamente recebidos", nos termos da seguinte ementa: "PREVIDÊNCIA SOCIAL. BENEFÍCIO PREVIDENCIÁRIO. ANTECIPAÇÃO DE TUTELA. REVERSIBILIDADE DA DECISÃO. O grande número de ações, e a demora que disso resultou para a prestação jurisdicional, levou o legislador a antecipar a tutela judicial naqueles casos em que, desde logo, houvesse, a partir dos fatos conhecidos, uma grande verossimilhança no direito alegado pelo autor. O pressuposto básico do instituto é a reversibilidade da decisão judicial. Havendo perigo de irreversibilidade, não há tutela antecipada (CPC, art. 273, § 2\%). Por isso, quando o juiz antecipa a tutela, está anunciando que seu decisum não é irreversível. Mal sucedida a demanda, o autor da ação responde pelo recebeu indevidamente. $\mathrm{O}$ argumento de que ele confiou no juiz ignora o fato de que a parte, no processo, está representada por advogado, o qual sabe que a antecipação de tutela tem natureza precária. Para essa solução, há ainda o reforço do direito material. Um dos princípios gerais do direito é o de que não pode haver enriquecimento sem causa. Sendo um princípio geral, ele se aplica ao direito público, e com maior razão neste caso porque o lesado é o patrimônio público. O art. 115, II, da Lei $\mathrm{n}^{\circ}$ 8.213, de 1991, é expresso no sentido de que os benefícios previdenciários pagos indevidamente estão sujeitos à repetição. Uma decisão do Superior Tribunal de Justiça que viesse a desconsiderá-lo estaria, por via transversa, deixando de aplicar norma legal que, a contrario sensu, o Supremo Tribunal Federal declarou constitucional. Com efeito, o art. 115, II, da Lei $\mathrm{n}^{\circ}$ 8.213, de 1991, exige o que o art. 130, parágrafo único na redação originária (declarado inconstitucional pelo Supremo Tribunal Federal - ADI 675) dispensava. Orientação a ser seguida nos termos do art. 543-C do Código de Processo Civil: a reforma da decisão que antecipa a tutela obriga o autor da ação a devolver os benefícios previdenciários indevidamente recebidos. Recurso especial conhecido e provido." (REsp 1.401.560/MT, Rel. Ministro SÉRGIO KUKINA, Rel. p/ Acórdão Ministro ARI PARGENDLER, PRIMEIRA SEÇÃO, julgado em 12/02/2014, DJe 13/10/2015). Na espécie, o acórdão combatido diverge dessa orientação na medida em que decidiu que não são repetíveis os valores relativos aos benefícios previdenciários pagos por força de tutela antecipada posteriormente revogada. Ante o exposto, $D O U$ PROVIMENTO ao recurso especial para determinar a devolução dos valores indevidamente recebidos por força de tutela antecipada, posteriormente revogada. Publique-se. Intimem-se. Brasília, 06 de agosto de 2018. MINISTRA LAURITA VAZ Presidente (STJ - REsp: 1754580 RS 2018/0180841-1, Relator: Ministra LAURITA VAZ, Data de Publicação: DJ 10/08/2018) (grifo nosso).

Cabe no entanto ressaltar que o Superior Tribunal de Justiça, em 03/12/2018, afetou a Pet 12482/DF e a tese firmada na discussão do Tema 692 encontra-se atualmente em revisão ${ }^{33}$, ademais, o egrégio tribunal determinou a suspensão do processamento de todos os processos ainda sem trânsito em julgado, individuais ou coletivos, que versem acerca da questão e tramitem no

\footnotetext{
33 Tribunal de Justiça do Estado de Minas Gerais - TJMG. Proposta de Revisão de Entendimento firmado em tese repetitiva firmada pela Primeira Seção relativa ao Tema 692/STJ (Tema 692 - STJ). Disponível em: http://www.tjmg.jus.br/portal-tjmg/jurisprudencia/recurso-repetitivo-e-repercussao-geral/proposta-de-revisao-deentendimento-firmado-em-tese-repetitiva-firmada-pela-primeira-secao-relativa-ao-tema-692-stj-tema-692stj.htm\#.XT4t15NKjOQ. Acesso em: 19 jul. 2019.
} 
território nacional (ressalvados os incidentes, questões e tutelas, que sejam interpostas a título geral de provimentos de urgência nos processos objeto do sobrestamento $)^{34}$

\subsubsection{Reversibilidade da Tutela Antecipada}

Um dos principais argumentos em que se baseia o Superior Tribunal de Justiça é na precariedade da tutela antecipada, isto é, na sua possibilidade de reversão por não se tratar de uma decisão definitiva, mas sim provisória. Inclusive, neste sentido, o Código de Processo Civil ao tratar da tutela de urgência em seu art. 300 , traz no $§ 3^{\circ}$, a previsão de que esta não será concedida se houver perigo de irreversibilidade ${ }^{35}$.

Alguns doutrinadores como Didier Jr. concordam com o que dispõe o referido dispositivo legal, tendo em vista que a tutela antecipada se baseia em um juízo de cognição sumária e juízo de verossimilhança, logo, a seu ver seria "prudente" que tais efeitos fossem reversíveis, em suas palavras "conceder uma tutela provisória satisfativa irreversível seria conceder a própria tutela definitiva” (DIDIER ET AL, 2017, p. 680).

Para o juiz federal Omar Chamon, "a reversibilidade das tutelas de urgência é elemento essencial desse instituto" de modo que quando há a concessão já se vislumbra a garantia de possa haver um retorno ao estado inicial anterior à essa concessão, senão não estaria respeitando a reversibilidade trazida em lei (CHAMON, 2018, p. 6).

Por sua vez, Marinoni, Arenhart e Mitidiero (2018, p. 414) consideram que essa vedação expressa no CPC vai de encontro à lógica da tutela provisória, cuja finalidade é exatamente "combater o perigo na demora" passível de causar um dano irreparável e irreversível. Em suas palavras "não admitir a concessão dessa tutela sob o simples argumento de que ela pode trazer um prejuízo irreversível ao réu. Seria como dizer que o direito provável deve sempre ser sacrificado diante da possibilidade de prejuízo irreversível ao direito improvável" o que seria para o autor um completo contrassenso.

\footnotetext{
34 Superior Tribunal de Justiça. Tema Repetitivo 692. Disponível em: http://www.stj.jus.br/repetitivos/temas_repetitivos/pesquisa.jsp?novaConsulta=true\&tipo_pesquisa=T\&sg_classe=R Esp\&num_processo_classe=1401560. Acesso em: 19 jul. 2019.

35 " $\S 3^{\circ}$ A tutela de urgência de natureza antecipada não será concedida quando houver perigo de irreversibilidade dos efeitos da decisão".
} 
4.2.2 Previsão legal do art. 115 da Lei 8213/91 e a proibição ao enriquecimento sem causa ante o erário público

O art. 115 da Lei 8213/91 que dispõe sobre os Planos de Benefícios da Previdência Social aduz que pode ser descontado do benefício o pagamento de benefício previdenciário ou assistencial indevido, ou além do devido, inclusive na hipótese de cessação do benefício pela revogação de decisão judicial.

No julgamento do REsp: 1401560 MT que firmou o entendimento do STJ, o próprio ministro relator apontou que o referido dispositivo é expresso no sentido de que os benefícios previdenciários pagos indevidamente estão sujeitos à repetição, de modo que "uma decisão do Superior Tribunal de Justiça que viesse a desconsiderá-lo estaria, por via transversa, deixando de aplicar norma legal que, a contrario sensu, o Supremo Tribunal Federal declarou constitucional"36.

Outro ponto que cabe ressaltar no prisma dessa questão diz respeito à discussão de Tema Repetitivo no 598 que teve o Leading Case REsp 1350804/PR, o STJ firmou a tese de que apesar do que está expresso em lei a inscrição em dívida ativa não seria o meio de cobrança adequado para os valores indevidamente recebidos a título de benefício previdenciário previstos no art. 115 , II, da Lei n. 8.213/91 e que estes deveriam se submeter-se a ação de cobrança por enriquecimento ilícito para apuração da responsabilidade $\operatorname{civil}^{37}$.

Assim, para que pudesse haver a inscrição em dívida ativa, a Lei 8213/91 passou a prever expressamente essa situação no $\$ 3^{\circ}$ do citado dispositivo, onde há a previsão de inscrição em dívida ativa dos créditos constituídos pelo INSS em decorrência desses benefícios pagos indevidamente (inclusive na hipótese de cessação do benefício pela revogação de decisão judicial - o que se aplicaria as situações de revogação de tutela antecipada) com redação dada pela Lei ${ }^{\circ}$ 13.846, de 2019.

O juiz relator do REsp: 1401560 MT apontou ainda que:

[...] quando o juiz antecipa a tutela, está anunciando que seu decisum não é irreversível. Mal sucedida a demanda, o autor da ação responde pelo recebeu indevidamente. O argumento de que ele confiou no juiz ignora o fato de que a parte, no processo, está representada por advogado, o qual sabe que a antecipação de tutela tem natureza precária.

\footnotetext{
${ }^{36}$ STJ - REsp: 1401560 MT 2012/0098530-1, Relator: Ministro SÉRGIO KUKINA, Data de Julgamento: 12/02/2014, S1 - PRIMEIRA SEÇÃO, Data de Publicação: DJe 13/10/2015.

37 Superior Tribunal de Justiça. Tema Repetitivo 598. Disponível em: http://www.stj.jus.br/repetitivos/temas_repetitivos/pesquisa.jsp?novaConsulta=true\&tipo_pesquisa=T\&cod_tema_ini cial=598\&cod_tema_final=598. Acesso em: 19 jul. 2019.
} 
Para essa solução, há ainda o reforço do direito material. Um dos princípios gerais do direito é o de que não pode haver enriquecimento sem causa ${ }^{38}$.

O enriquecimento encontra-se expresso legalmente no artigo 884 do Código Civil, o qual aduz "aquele que, sem justa causa, se enriquecer à custa de outrem, será obrigado a restituir o indevidamente auferido, feita a atualização dos valores monetários”. Assim na concepção do ministro relator, na revogação da tutela, a pessoa apenas devolve aquilo que não é seu, de modo que não havendo esse retorno, consubstanciará um enriquecimento sem causa.

\subsection{A Súmula 51 da TNU}

Tendo em vista a grande controvérsia sobre a devolução das verbas previdenciárias em caso de posterior revogação da tutela antecipada, a Turma Nacional de Uniformização (TNU) editou a Súmula 51 em 15/03/2012 a qual dispunha que "Os valores recebidos por força de antecipação dos efeitos de tutela, posteriormente revogada em demanda previdenciária, são irrepetíveis em razão da natureza alimentar e da boa-fé no seu recebimento".

Ocorre que diante das controvérsias jurisprudenciais que vimos, em 30/08/2017, tendo em vista o imbroglio que tais divergências vinham causando no cenário jurídico, a mantença da Súmula 51 não restava mais coerente. Deste modo, no Pedido de Uniformização de Interpretação do tema 23 , PEDILEF 5000711-91.2013.4.04.7120/PR, buscando adequar o seu entendimento ao do Superior Tribunal de Justiça sobretudo após o emblemático caso REsp n. 1.401.560/MT, a TNU cancelou a referida súmula ${ }^{39}$.

No relatório ${ }^{40}$, de autoria do Juiz Federal Relator Douglas Camarinha Gonzales, alguns pontos importantes foram levados em consideração: o STJ decidiu mediante a emblemática REso n. 1.401.560/MT pugnou pela obrigatoriedade da devolução dos benefícios previdenciários indevidamente recebidos. Um dos fundamentos foi o embasamento legal do art. 115 da Lei de Benefícios Previdenciários, nesse sentido, o Juiz Douglas Gonzales apontou que "a respeito da responsabilidade do beneficiário em caso de recebimento além do devido, situação que converge

\footnotetext{
${ }^{38}$ STJ - REsp: 1401560 MT 2012/0098530-1, Relator: Ministro SÉRGIO KUKINA, Data de Julgamento: 12/02/2014, S1 - PRIMEIRA SEÇÃO, Data de Publicação: DJe 13/10/2015.

39 Conselho da Justiça Federal. TNU cancela enunciado da Súmula $\mathbf{n}^{\mathbf{0}} \mathbf{5 1}$. Disponível em: https://www.cjf.jus.br/cjf/noticias/2017/setembro/tnu-cancela-enunciado-da-sumula-no-51. Acesso em: 19 jul. 2019.

40 Turma Nacional de Uniformização dos Juizados Especiais Federais. PROCESSO $\mathbf{N}^{\mathbf{0}}$ 500071191.2013.4.04.7120. Disponível em: https://www2.jf.jus.br/phpdoc/virtus/uploads/lXUboNoz.pdf. Acesso em: 14 jul. 2019.
} 
para a devolução daquilo que não é seu direito, já que é princípio basilar, tanto na ética quanto no direito, que ninguém pode dispor do que não possui”.

Ademais, ressaltou que o STF passou a não admitir interposição de Recurso Extraordinário (conforme vimos, essa foi a tese firmada na discussão do Tema 799) de modo que a matéria não mais comporta exame do Supremo Tribunal Federal.

Em suma, tendo em vista que a autoridade máxima a se manifestar sobre o assunto é atualmente o Superior Tribunal de Justiça (STJ), considerando que a matéria não é mais cabível de ser apreciada pelo STJ, não fazia mais sentido vigorar a Súmula 51 da TNU, a qual foi prontamente cancelada pelo tribunal.

\section{JURISPRUDENCIA DOS TRIBUNAIS REGIONAIS FEDERAIS DA $3^{\mathrm{a}}$ E $4^{\mathrm{a}}$ REGIÃO}

Diante de toda essa controvérsia gerada pelos Tribunais Superiores, não causa estranheza que tenha havido uma reflexa divergência jurisprudencial nos tribunais inferiores, que hodiernamente ainda vem aplicando posicionamentos divergentes quanto à matéria. Vejamos alguns julgados recentes dos tribunais regionais federais da $3^{\mathrm{a}}$ e $4^{\mathrm{a}}$ região:

PREVIDENCIÁRIO. DECISÃO JUDICIAL QUE REVOGA CONCESSÃO. TUTELA ANTECIPADA. REVOGAÇÃO. DEVOLUÇÃO DOS VALORES RECEBIDOS. Não obstante o julgamento do Tema 692 pelo STJ, a Terceira Seção deste Tribunal tem entendimento consolidado no sentido de não caber devolução dos valores recebidos a título de tutela antecipada posteriormente revogada, em razão do caráter alimentar dos recursos percebidos de boa-fé. (TRF-4 - APL: 50108365720134047108 RS 501083657.2013.4.04.7108, Relator: GISELE LEMKE, Data de Julgamento: 17/04/2018, QUINTA TURMA)

Verifica-se que o TRF4, apesar de expressamente declarar ciência do posicionamento consolidado do STJ, continua a firmar entendimento diverso, pela não devolução dos valores recebidos a título de tutela antecipada posteriormente em razão do caráter alimentar das verbas. Tal posicionamento remete ao posicionamento inicial do STF sobre o assunto, conforme vimos no ARE 734199 e no ARE no 734.242/DF-AgR.

Vejamos agora os seguintes julgados do TRF3:

PREVIDENCIÁRIO. DEVOLUÇÃO DE VALORES RECEBIDOS A TÍTULO DE TUTELA ANTECIPADA. - A propósito dos pagamentos efetuados em cumprimento a decisões antecipatórias de tutela, não se desconhece o julgamento proferido pelo C. STJ 
no Recurso Especial Representativo de Controvérsia $n^{\circ}$ 1.401.560/MT, que firmou orientação no sentido de que a reforma da decisão que antecipa a tutela obriga o autor da ação a devolver os benefícios previdenciários indevidamente recebidos. - Todavia, é pacífica a jurisprudência do E. STF, no sentido de ser indevida a devolução de valores recebidos por força de decisão judicial antecipatória dos efeitos da tutela, em razão da boa-fé do segurado e do princípio da irrepetibilidade dos alimentos. - Tem-se, ainda, que o Pleno do Supremo Tribunal Federal, ao julgar o Recuso Especial n. 638115, já havia decidido pela irrepetibilidade dos valores recebidos de boa fé até a data do julgamento. A sentença não merece reforma, pois está em consonância com o entendimento do Colendo Supremo Tribunal Federal. - Apelo improvido. (TRF-3 - AC: 00021607820154036102 SP, Relator: DESEMBARGADORA FEDERAL TANIA MARANGONI, Data de Julgamento: 21/08/2017, OITAVA TURMA, Data de Publicação: e-DJF3 Judicial 1 DATA:04/09/2017)

PREVIDENCIÁRIO. PROCESSUAL CIVIL. REMESSA OFICIAL NÃO CONHECIDA. APOSENTADORIA POR INVALIDEZ OU AUXÍLIO-DOENÇA. AUSÊNCIA DE INCAPACIDADE TOTAL. LAUDO PERICIAL. REQUISITOS NÃO PREENCHIDOS. BENEFÍCIOS INDEVIDOS. DEVOLUÇÃO VALORES. TUTELA ANTECIPADA. APELAÇÃO DO INSS PROVIDA. - A remessa oficial não deve ser conhecida, por ter sido proferida a sentença na vigência do Novo CPC, cujo artigo 496, § $3^{\circ}$, I, afasta a exigência do duplo grau de jurisdição quando a condenação ou o proveito econômico for inferior a 1.000 (mil) salários-mínimos. No caso, a toda evidência não se excede esse montante. - São exigidos à concessão dos benefícios: a qualidade de segurado, a carência de doze contribuições mensais - quando exigida, a incapacidade para o trabalho de forma permanente e insuscetível de recuperação ou de reabilitação para outra atividade que garanta a subsistência (aposentadoria por invalidez) e a incapacidade temporária (auxílio-doença), bem como a demonstração de que o segurado não era portador da alegada enfermidade ao filiar-se ao Regime Geral da Previdência Social. - No caso, a perícia judicial concluiu pela incapacidade parcial e permanente, podendo exercer suas atividades habituais. - Não patenteada a contingência necessária à concessão do benefício pleiteado, pois ausente a incapacidade total para o trabalho, temporária ou definitiva, merecendo ser reformada a sentença. - Requisitos para a concessão do benefício de aposentadoria por invalidez ou auxílio-doença não preenchidos. - Os valores antecipados em tutela específica deverão ser devolvidos, consoante determina o CPC, bem assim à luz dos precedentes do Superior Tribunal de Justiça (REsp 1.384.418 e REsp 988.171). Invertida a sucumbência, condeno a parte autora a pagar custas processuais e honorários de advogado, arbitrados em $12 \%$ (doze por cento) sobre o valor atualizado da causa, já majorados em razão da fase recursal, conforme critérios do artigo $85, \S \S 1^{\circ}, 2^{\circ}, 3^{\circ}, \mathrm{I}, \mathrm{e} 4^{\circ}$, III, do Novo CPC. Porém, fica suspensa a exigibilidade, na forma do artigo $98, \S 3^{\circ}$, do referido código, por ser beneficiária da justiça gratuita. - Remessa oficial não conhecida. Apelação do INSS provida. (TRF-3 - ApReeNec: 00244064620174039999 SP, Relator: JUIZ CONVOCADO RODRIGO ZACHARIAS, Data de Julgamento: 27/11/2017, NONA TURMA, Data de Publicação: e-DJF3 Judicial 1 DATA:12/12/2017).

Verifica-se que em um curto lapso temporal, em um mesmo tribunal houveram dois julgados com decisões diametralmente opostas, uma exaltando expressamente o entendimento do Superior Tribunal de Justiça pela devolução dos valores recebidos e a outra manifestamente adepta ao entendimento inicial do STF pela irrepetibilidade dos benefícios previdenciários recebidos.

Nesse sentido, podemos concluir que a divergência de entendimento entre o STJ e o STF provocam certa insegurança quando se trata da discussão sobre a devolução ou não de valores 
recebidos por tutela antecipada posteriormente revogada, tendo em vista que permitem uma interpretação inconstante pelos demais tribunais.

\section{CONSIDERAÇÕES FINAIS}

Diante do crescimento das demandas previdenciárias, a demora na conclusão das lides para que pudesse haver a efetiva prestação jurisdicional, e tendo de uma situação de urgência e necessidade que em regra se encontra o solicitante do benefício, levou à necessidade de se antecipar a tutela judicial em tais situações para que o a fruição do direito do beneficiário não restasse prejudicada.

Nesse ínterim, surgem diversas consequências advindas desse ato, a concessão da tutela antecipada em tais casos não vislumbrou a repercussão posterior em caso de revogação da tutela, causando divergência de posicionamento nas cortes brasileiras, é cabível ou não a devolução desses valores?

Conforme verificamos, o Supremo Tribunal Federal, à priori, ao decidir sobre o tema, pugnou pela irrepetibilidade dos valores recebidos mediante concessão de benefícios, ainda que por tutela provisória, tendo em vista o caráter alimentar de tais verbas as quais destina-se a prover recursos de subsistência digna para os beneficiários, além disso, estes não teriam como dispor de parte delas continuamente para precaver-se de uma eventual reversão da decisão, tendo em vista que depende de tais verbas para a sua alimentação ou aquisição de medicamentos essenciais, por exemplo. Um segundo argumento trazido pela corte foi o da boa-fé e segurança jurídica, os quais constituem importantes princípios do ordenamento jurídico brasileiro, e dos quais decorre a confiança do cidadão na atuação estatal.

O Superior Tribunal de Justiça, por sua vez, se dá no sentido da necessidade de devolução dos valores recebidos por antecipação de tutela posteriormente revogada, tendo em vista o caráter precário de tal tutela, que implica em sua possível reversibilidade posterior, inclusive havendo previsão legal expressa nesse sentido. Ademais, aponta que existe ainda previsão legal para a devolução dos valores no art. 115 da Lei 8213/91, lei que dispõe dos Planos de Benefícios da Previdência, de modo que a apropriação de valores que não pertencem ao beneficiário constituiria uma forma de enriquecimento sem causa ante o erário público. 
Apesar do entendimento firmado pelo STF o paradigma muda a partir da ARE 722421, quando o egrégio Tribunal decidiu pela não admissibilidade de tais casos por se tratar de matéria infraconstitucional, deixando a partir de então, a solução à cargo do posicionamento do STJ, cujo entendimento passa a ser o magnânimo em tais situações. Ademais, mesmo o próprio STJ decidiu revisar sua tese que atualmente ainda se encontra em discussão através do Tema 692.

Tais divergências nos tribunais superiores brasileiros, repercutiram nas esferas inferiores, causando um completo desalinhamento nas interpretações e decisões que versam sobre o assunto. Como vimos, em recentes julgados dos Tribunais Regionais Federais da $3^{\mathrm{a}}$ e $4^{\mathrm{a}}$ regiões, existem decisões dadas pelas duas vertentes, o que reflete um contexto de insegurança jurídica diante da incerteza incutida na resolução das lides que versam sobre a matéria.

\section{REFERÊNCIAS}

BALERA, Wagner; RAEFFRAY, Ana Paula Oriola de (Coord). Processo previdenciário: teoria e prática. São Paulo: Conceito, 2012. ISBN: 9788578742492.

BRASIL. Constituição (1988). Constituição da República Federativa do Brasil. Brasília, Disponível em: http://www.planalto.gov.br/ccivil_03/constituicao/constituicaocompilado.htm. Acesso em: 15 jul. 2019.

BRASIL Lei n. 8.213, de 24 de julho de 1991. Brasília. Disponível em: http://www.planalto.gov.br/ccivil_03/leis/L8213cons.htm. Acesso em: 15 jul. 2019.

BRASIL. Lei no 10.259, de 12 de julho de 2001. Brasília, Disponível em: http://www.planalto.gov.br/ccivil_03/Leis/LEIS_2001/L10259.htm. Acesso em: 15 jul. 2019.

BRASIL. Lei no 13.105, de 16 de março de 2015. Código de processo civil. Disponível em: http://www.planalto.gov.br/ccivil_03/_Ato2015-2018/2015/Lei/L13105.htm. Acesso em: 15 jul. 2019.

BRASIL. STF. Supremo mantém liminarmente acumulação de aposentadoria de professor. Disponível em: http://m.stf.gov.br/portal/noticia/verNoticiaDetalhe.asp?idConte udo=67610. Acesso em: 15 jul. 2019.

CHAMON, Omar. Tutela revogada e devolução dos valores. REVISTA BRASILEIRA DE DIREITO SOCIAL, v. 1, n. 2, p. 5-15, 24 jun. 2018.

CONSELHO NACIONAL DE JUSTIÇA, Justiça em números: 2018. Brasília, 2018. Disponível em: http://www.cnj.jus.br/files/conteudo/arquivo/2018/08/44b7368ec6f888b383 f6c3de40c32167 .pdf. Acesso em: 15 jul. 2019. 
CONSELHO DA JUSTIÇA FEDERAL. TNU cancela enunciado da Súmula $\mathbf{n}^{0} 51$. Disponível em: https://www.cjf.jus.br/cjf/noticias/2017/setembro/tnu-cancela-enunciado-da-sumula-no-51. Acesso em: 19 jul. 2019.

DESTRO, Letícia Giusti. POSSIBILIDADE DE RESTITUIÇÃO DE VALORES PREVIDENCIÁRIOS RECEBIDOS POR TUTELA ANTECIPADA POSTERIORMENTE REVOGADA. 2018. 73 f. TCC (Graduação) - Curso de Direito, Universidade do Sul de Santa Catarina, Araranguá, 2018.

DIDIER JUNIOR, Fredie (et al). Curso de direito processual civil. 19. ed. rev. ampl. e atual. Salvador, BA: Juspodivm, 2017. 5 v. ISBN: 9788544210109.

FONSÊCA, Vitor. A Súmula 729 do STF e o CPC/2015. Revista de Processo (MPSP), v. 248, p. 357-368, 2015. p. 359.

GOMES, Amanda Garcia. TUTELA PROVISÓRIA EM FACE DO INSTITUTO NACIONAL DO SEGURO SOCIAL - INSS.2019. 37 f. TCC (Graduação) - Curso de Direito, Unievangélica, Anápolis, 2019.

KERTZMAN, Ivan. Curso prático de direito previdenciário. 9. ed. Salvador: JusPodivm, 2012. ISBN: 8577614549.

MARINONI, Luiz Guilherme; ARENHART, Sérgio Cruz; MITIDIERO, Daniel Francisco. Código de processo civil comentado. 4. ed. rev., atual. e ampl. São Paulo: Thomson Reuters. Revista dos Tribunais, 2018. ISBN: 9788553210299.

NEVES, Daniel Amorim Assumpção. Manual de direito processual civil - Volume único. 10. ed. rev., ampl. e atual. Salvador: JusPodivm, 2018. 1807p. ISBN: 9788544219447.

NUNES, Elpídio Donizetti. Curso didático do direito processual civil. 19. ed. rev., ampl. e atual. Rio de Janeiro: Atlas, 2016. 1587 p. ISBN: 9788597003864.

PINTO NETTO, Luisa Cristina. Ato de aposentadoria. Natureza jurídica, registro pelo Tribunal de Contas e decadência. Revista Brasileira de Direito Público. Belo Horizonte: Fórum, ano 4, n. 13, abr/jun. 2006.

RAATZ, Igor; ANCHIETA, Natascha. Tutela antecipada, tutela cautelar e tutela da evidência como espécies de tutela provisória no novo Código de Processo Civil. Revista Eletrônica de Direito Processual, v. 15, n. 15, 2015.

SAVARIS, José Antonio. Direito processual previdenciário. 3. ed. Curitiba: Juruá Ed, 2011. ISBN: 9788536219684.

Superior Tribunal de Justiça. Tema Repetitivo 692. Disponível em: http://www.stj.jus.br/repetitivos/temas_repetitivos/pesquisa.jsp?novaConsulta=true\&tipo_pesquis a=T\&sg_classe=REsp\&num_processo_classe=1401560. Acesso em: 19 jul. 2019. 
Superior Tribunal de Justiça. Tema Repetitivo 598. Disponível em: http://www.stj.jus.br/repetitivos/temas_repetitivos/pesquisa.jsp?novaConsulta=true\&tipo_pesquis a=T\&cod_tema_inicial=598\&cod_tema_final=598. Acesso em: 19 jul. 2019.

THEODORO JÚNIOR, Humberto. As liminares e a tutela de urgência. Revista da Emerj, Rio de Janeiro, v. 5, n. 17, p.24-52, 2002. Trimestral.

Tribunal de Justiça do Estado de Minas Gerais - TJMG. Proposta de Revisão de Entendimento firmado em tese repetitiva firmada pela Primeira Seção relativa ao Tema 692/STJ (Tema 692 - STJ). Disponível em: http://www.tjmg.jus.br/portal-tjmg/jurisprudencia/recurso-repetitivo-erepercussao-geral/proposta-de-revisao-de-entendime nto-firmado-em-tese-repetitiva-firmadapela-primeira-secao-relativa-ao-tema-692-stj-tema-692-stj.htm\#.XT4t15NKjOQ. Acesso em: 19 jul. 2019.

Turma Nacional de Uniformização dos Juizados Especiais Federais. PROCESSO No 500071191.2013.4.04.7120. Disponível em: https://www2.jf.jus.br/phpdoc/virtus/uploads/lXUboNoz.pdf. Acesso em: 14 jul. 2019.

\title{
THE RETURN OF AMOUNTS RECEIVED BY PROVISIONAL BENEFITS GRANTED BY A FURTHER DECLARED EARLY TUTLE: JURISPRUDENTIAL ANALYSIS OF THE BRAZILIAN SUPERIOR COURTS
}

\begin{abstract}
The possibility of the return of amounts received for social security benefits granted through "early protection" that can be revoked later, is a theme that has gained notoriety and relevance in the legal community in view of the jurisprudential differences that have been verified in the Brazilian courts when judging such claims. Actions concerning the granting of social security benefits usually demand urgency in view of the situation of need and helplessness of the applicant; In addition, the time-lapse for the social security process to be completed may jeopardize the beneficiary's right and may lead to irreparable and irreversible damage to the claim. In such situations, it is not uncommon for protection to be required before the right can be fulfilled in a timely manner. However, such a decision is made by summary cognition, and the provisional nature of the guardianship implies that it may be posterior reversed. In case of revocation, the question is: is it appropriate to return these values? Given this, the present article seeks to analyze this possibility from a study on institute of "early protection" in the social security process, verifying how the Brazilian courts have been manifesting on the subject. It uses as methodological procedures the bibliographic research in print and virtual.
\end{abstract}


Keywords: social security law. social security benefits. social security process. anticipated tutle repeal. return of values. 